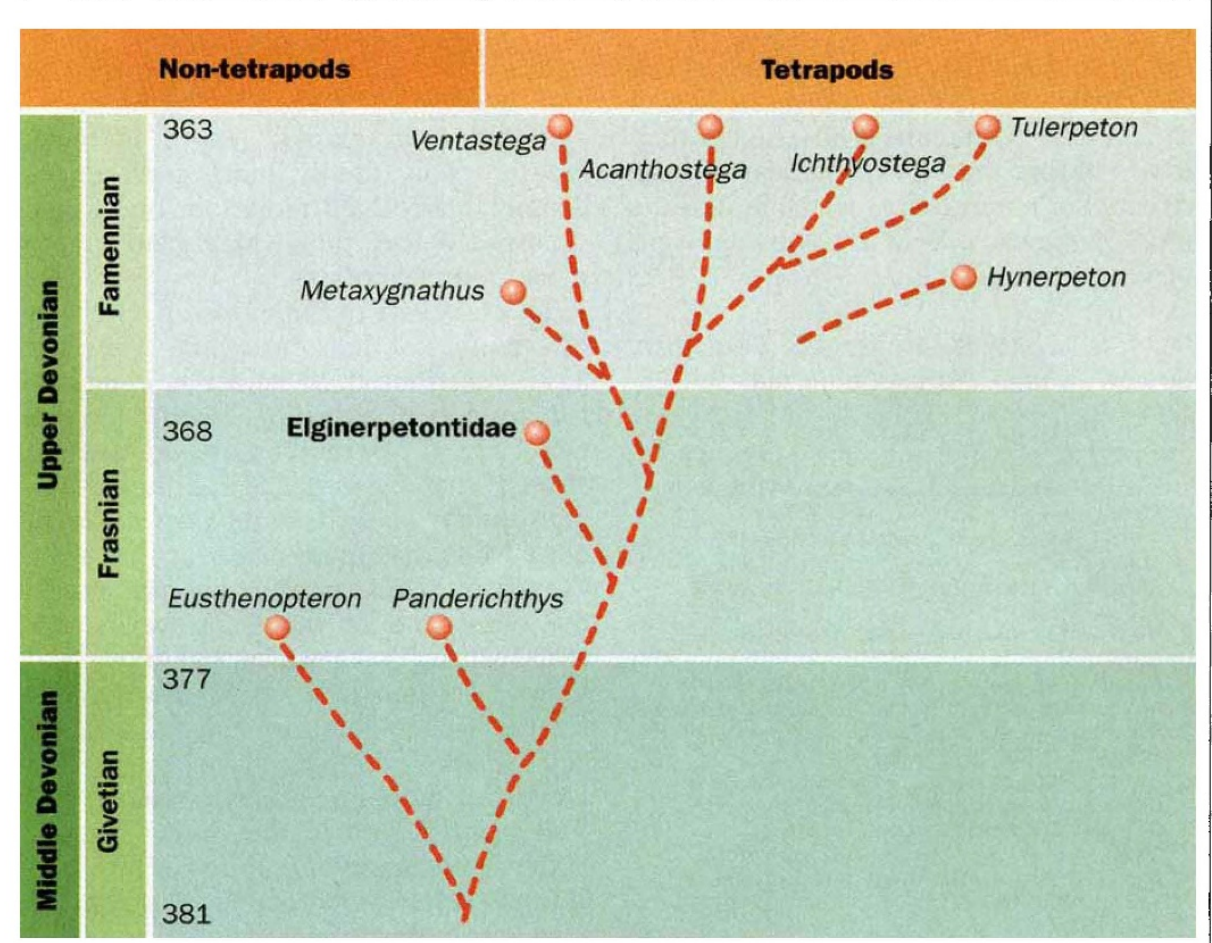

FIG. 2 The fish-amphibian transition. Temporal distribution of advanced osteolepiform fish and Devonian amphibians. Circles indicate time of occurrence of known fossils; dashed lines show possible relationships as discussed by Ahlberg ${ }^{1}$; and the numbers indicate ages in millions of years.

indicate that skeletal features that were once thought to be unique to land vertebrates appeared stepwise in a succession of aquatic, semiaquatic and semiterrestrial vertebrates, while features commonly attributed to fish were retained in animals classified as amphibians. This point is highlighted by evidence, provided by Coates and $\mathrm{Clack}^{8}$, that important features of the tetrapod hands and feet in Acanthostega may have evolved among primarily aquatic animals. The distribution of primitive and derived characters differs from lineage to lineage, showing that many features were evolved or lost convergently. As in the case of other major transitions in vertebrates, such as the origin of birds and mammals ${ }^{12,13}$, the convergent origin of derived features in different lineages makes it difficult to establish specific relationships, or to agree on objective criteria to differentiate tetrapods from their fish ancestors.

Although all these new data make it more difficult to classify species involved in the transition between fish and amphibians, they greatly illuminate the evolutionary processes involved. They demonstrate that the complete transition, from early osteolepiform sarcopterygians to primarily terrestrial amphibians may have extended over at least 15 million years. The fossil record is not yet well enough known to establish rates of evolution, but the observed changes may be attributed to progressive adaptation to increasingly shallow water, accompanied by repeated cladogenesis (branching of evolutionary lineages).
The increase of information on the fish-amphibian transition emphasizes the continued lack of knowledge of the next crucial step in the evolution of land verteknown Upper Devonian tetrapods, no amphibians have yet been described from the succeeding 20 million years, during which time all the main groups of later land vertebrates diverged.

Robert Carroll is in the Department of Biology, McGill University, 1205 DrPenfield Avenue, Montréal, Québec, Canada H3A $1 B 1$.

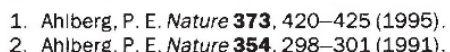

3. Vorobyeva, E. I. Trudy paleont. inst. 163,1-239 (1977).

4. Vorobyeva, E.I. \& Schultze, H.-P. in Origin of Higher Groups of Tetrapods: Controversy and Consensus (eds Schultze, H.-P. \& Trueb, L.) 68-109 (Cornell Univ. Press, Ithaca, 1991).

5. Clack, J. A. Nature 369, 392-394 (1994).

6. Coates, M. I. \& Clack, J. A. Nature 347, 66-69 (1990).

7. Coates, M. I. \& Clack, J. A. Nature 352, 234-235 (1991).

8. Coates, M. 1. \& Clack, J. A in Proc. Vile Symposium International Étude des Vertebrés inférieurs (in the press). K. S. T. \& Amaral, W. W. Science 265, 639-642 (1994).

10. Lebedev, O. A. \& Clack, J. A. Palaeontology 36, 721-734 (1993).

11. Thomson. K. S. T. in Major Features of Vertebrate Evolution (ed. Spencer, R.) 85-107 (Paleontological Society, Dept Geol. Sci., Univ. Tennessee, Knoxvilie, 1994).

12. Ostrom. J. H. in Major Features of Vertebrate Evolution (ed. Spencer, R.).160-177 (Paleontological Society, Dept Geol. Sci., Univ. Tennessee, Knoxville 1994).

13. Hopson, J. A. in Major Features of Vertebrate Evolution (ed. Spencer. R.) 190-219 (Paleontological Society, Dept Geol. Sci., Univ. Tennessee, Knoxville 1994). brates. In contrast to the variety of well-

9. Daeschler, E. B., Shubin, N. H., Thomson.

\section{Rolling foam}

THE hovercraft supports itself on a cushion of air that leaks away so rapidly that it has to be replaced all the time by continuous fast pumping. Daedalus now proposes a hovercraft pumped not with air, but with detergent foam.

Foam, he reckons, acts like a gas that can sustain a pressure gradient. Every film wall in the foam has a pressure difference across it; the sharper the film curvature the greater this pressure drop. A foam of many small bubbles is a multitude of sharply curved films in series, and can contain quite a large pressure. Special detergent foams have already been proposed to impede rioters and reduce the force of terrorist bombs. With a little development, they should be able to support a hovercraft.

Daedalus's foamcraft will be essentially a flat platform with a hole in the middle. Into the hole will be pumped, not pure air, but detergent foam. Under the craft, it will spread out into a soft supporting cushion which will leak out round the edges only slowly. A very small pump will keep the vehicle foamborne.

The foamcraft could drive itself along in several ways. It could use the usual inefficient airscrews. A seagoing foamcraft could project a propeller shaft down through the foam into the water. On land it might use wheels or a caterpillar track, touching the ground but not loading it with much weight. While fitting the craft for its most obvious use moving heavy loads over rough or marshy country - this would destroy much of its elegance. But Daedalus hopes that the foam itself can be made to exert a tractive force. By angling the jets delivering the foam, or spinning small paddle-wheels within it, it might be given a rotatory swirl which would turn it into a sort of fluid caterpillar track. The more viscous the foam, the greater traction it could exert, but at the cost of higher viscous losses. Careful optimization wil be needed.

At first Daedalus imagined that his foamcraft would leave a glistening trail of foam behind it, like some giant mollusc. But he is now designing a simple foamsucker at the back to scoop up this trail and recycle it. This would almost eliminate losses of water and detergent, making the craft nearly self-contained. Calmly and smoothly, with no blasts of air and no roaring, foamcraft will glide across water, along beaches, over marsh and moor and even along ordinary roads. Their cushion of churning detergent foam could make them ideal for street cleaning duties. Pedestrians run over by a foamcraft would not be injured, but merely subjected to a brisk Jacuzzi experience.

David Jones 